\title{
India's COVID-19 Testing Strategy: Why Pediatric Hospitals Need to Focus More on ILI than SARI?
}

\author{
Nabaneeta Dash ${ }^{1} \cdot$ Pusp Raj Awasthi ${ }^{2} \cdot$ Karthi Nallasamy ${ }^{2}$ (D)
}

Received: 20 May 2020 / Accepted: 29 May 2020 / Published online: 10 June 2020

(C) Dr. K C Chaudhuri Foundation 2020

To the Editor: India reports total and state wise tally of coronavirus disease (COVID-19) cases daily, but epidemiology and clinical characteristics in children remain unclear. Revised testing strategy (ICMR_v5) emphasized on influenza like illness (ILI) in addition to severe acute respiratory illness (SARI). This approach does not differentiate between patients of different age groups. Globally, COVID-19 incidence in children is lower. In China, Italy and USA, children $<18$ y represented $2.4 \%$, $2.1 \%$ and $1.7 \%$ cases respectively [1-3]. Data from India is not accessible, however report from Tamilnadu, a highly affected state, revealed $6 \%(747$ out of 12,448$)$ cases in $0-12$ y age group. The illness severity also seems milder in children. Hospitalization (5.7-20\%) and intensive care (0.6-2\%) needs were low in USA [2]. Of 731 Chinese children, asymptomatic $(12.9 \%)$, mild (43.1\%) upper respiratory illness (URI) and moderate $(41 \%)$ disease without dyspnea/hypoxemia accounted the most. Very few had severe $(2.5 \%)$ or critical $(0.4 \%)$ illness [3]. Hospitalization rate in India is unknown, but even if available can be misleading, as most children were admitted along with the adult family members as containment measure irrespective of illness severity.

Hospital-based SARI surveillance showed that among 5911 patients across 41 sites, only 104 (1.8\%) were positive for COVID-19. Test positivity increased from $0 \%$ before March 14, to $2.6 \%$ by April 2, 2020, however it was $0.2 \%$ ( 2 out of 757 ) in children $\leq 19$ y [4]. In our tertiary Pediatric Emergency Unit, of 141 consecutive children with SARI tested between April 03 and May 17, 2020, one (0.7\%) was positive. As India is under extended lockdown with suspension of

Karthi Nallasamy

ny.karthi@gmail.com

1 Pediatric Infectious Diseases Unit, Christian Medical College and Hospital, Vellore, Tamil Nadu, India

2 Pediatric Emergency and Intensive Care Unit, Department of Pediatrics, Postgraduate Institute of Medical Education and Research, Chandigarh, India schools and outdoor activities, primary source of contact for children would be an infected adult family member. Hence testing children as a part of family cluster would remain most appropriate. Hospital-based SARI testing in children is associated with poor pre-test probability due to lower infection rate and higher prevalence of mild symptoms. As URI constitutes about $50 \%$ of symptoms, screening children with ILI would be a more prudent approach besides continuing to screen SARI. Pooled sample testing can also be explored for ILI cases at larger hospitals as it is a more judicious approach in using precious laboratory resources [5].

\section{Compliance with Ethical Standards}

Conflict of Interest None.

\section{References}

1. Istituto Superiore di Sanità. Epidemia COVID-19. May 7, 2020. Available at: https://www.epicentro.iss.it/coronavirus/bollettino/ Bollettino-sorveglianza-integrata-COVID-19_7-maggio-2020.pdf Accessed May 16, 2020.

2. CDC COVID-19 Response Team. Coronavirus disease 2019 in children - United States, February 12-April 2, 2020. Morb Mortal Wkly Rep. 2020;69:422-6.

3. Lu X, Zhang L, Du H, et al; Chinese Pediatric Novel Coronavirus Study Team. SARS-CoV-2 infection in children. N Engl J Med. 2020;382:1663-5.

4. Gupta N, Praharaj I, Bhatnagar T, et al; ICMR COVID Team. Severe acute respiratory illness surveillance for coronavirus disease 2019 , India, 2020. Indian J Med Res. 2020;151:236-40.

5. Deckert A, Bärnighausen T, Kyei N. Pooled-sample analysis strategies for COVID-19 mass testing: A simulation study. Bull World Health Organ. 2 April 2020 (preprint). Available at: https://www. who.int/bulletin/online_first/20-257188.pdf. Accessed 16 May 2020.

Publisher's Note Springer Nature remains neutral with regard to jurisdictional claims in published maps and institutional affiliations. 